\title{
On-Flow Immobilization of Polystyrene
}

\section{Microspheres on $\beta$-Cyclodextrin Patterned Silica}

\section{Surfaces through Supramolecular Host-Guest}

\section{interactions}

Stan B.J. Willems ${ }^{\dagger \S}$, Anton Bunschoten ${ }^{\dagger \S}$, R. Martijn Wagterveld", Fijs W.B. van Leeuwen ${ }^{\dagger \S}$ and Aldrik H. Velders ${ }^{* \dagger} \S$

${ }^{\dagger}$ Laboratory of BioNanoTechnology, Wageningen University and Research, Axis, Bornse Weilanden 9, 6708 WG Wageningen, the Netherlands

§Interventional Molecular Imaging Laboratory, Department of Radiology, Leiden University and Medical Centre, 2300 RC Leiden, the Netherlands

"Wetsus, European Centre of Excellence for Sustainable Water Technology, Oostergoweg 9, 8911 MA Leeuwarden, the Netherlands

*to whom correspondence should be addressed: aldrik.velders@wur.nl 


\section{Table of Contents}

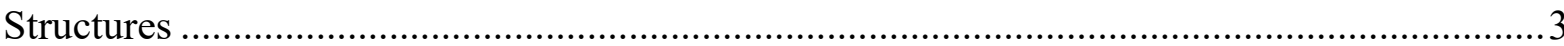

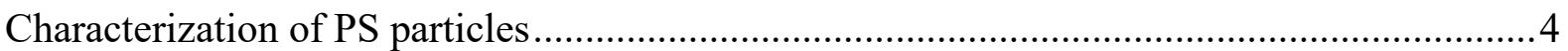

Dimensions of Micronit ${ }^{\circledR}$ flow cell and Comsol flow channel .............................................5

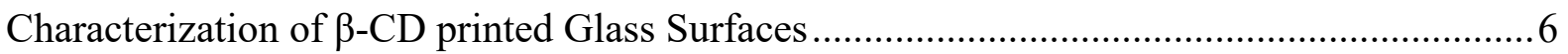

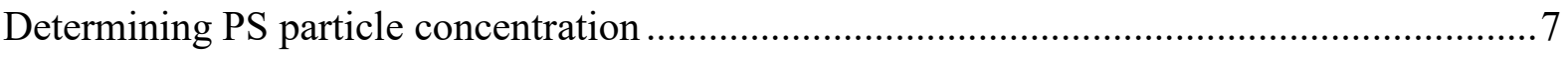

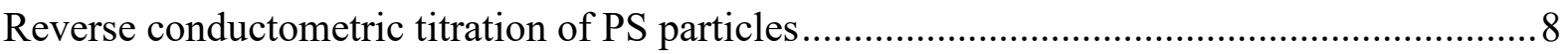

NMR analysis of supernatants from PS-Ad particles .........................................................

Stokes drag force, Reynolds numbers, Péclet number of particles at different flow rates ...... 13

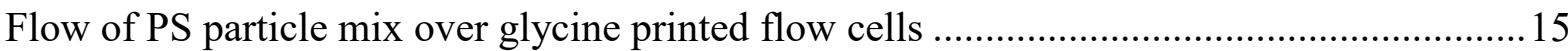

All flow rate variation experiments for PS-Cy5.5-0.8Ad and PS-Cy3 particles over $\beta$-CD

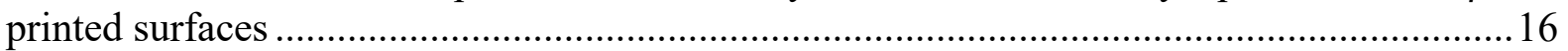

PS particle distribution after $0.25 \mu \mathrm{L} / \mathrm{min}$ flow rate of 20 hours......................................... 17

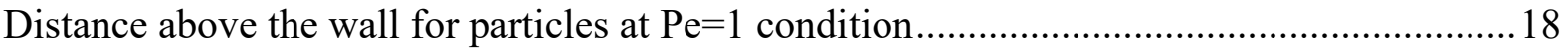

Quantitative analysis of PS-Cy3 particle density (in PS particle mix) with different flow rates of PS particle mix solution and different Ad loadings on PS-Cy5.5-Ad .............................. 19

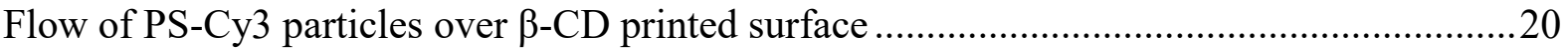




\section{Structures}

$$
\text { Cy3 }
$$

Cy5.5
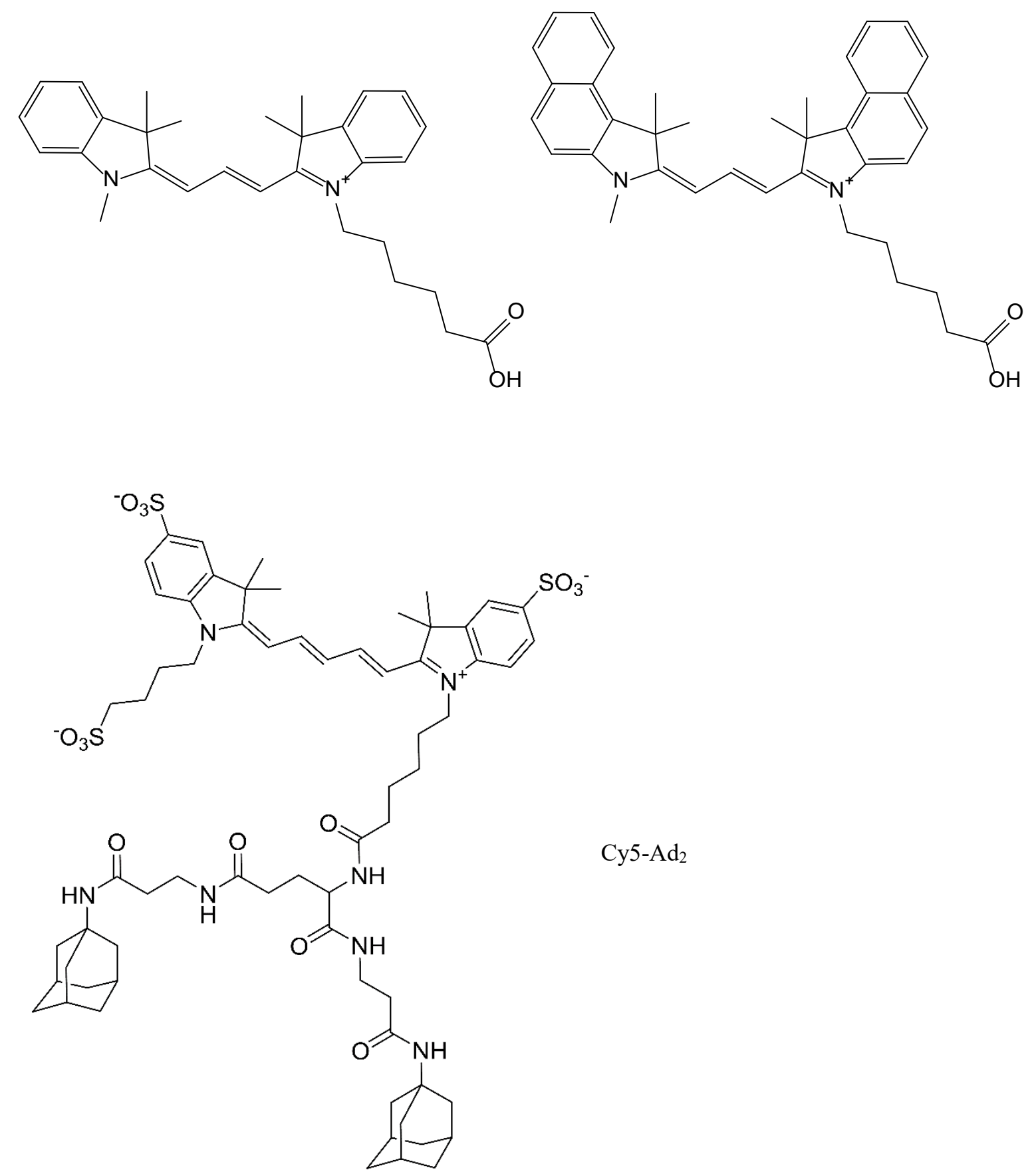

Figure S1: Structures of dye molecules used. Cy3 and Cy5.5 were used to stain the PS particles. Cy5- $\mathrm{Ad}_{2}$ was used for labelling $\beta$-CD patterns on glass slides 


\section{Characterization of PS particles}

DLS measurements were carried out after the synthesis of fluorescent PS particles and functionalization with adamantane in order to validate their size. According to the protocol from Appel et al.,the reported size with DLS was $1038 \mathrm{~nm}$ for pSIA25 latex particles ${ }^{1}$. Figure $\mathrm{S} 1$ shows that the size of synthesized PS particles is around this value. The depicted results are averages from 3 repeat measurements and the concentration of samples is $60 \mathrm{fM}$.

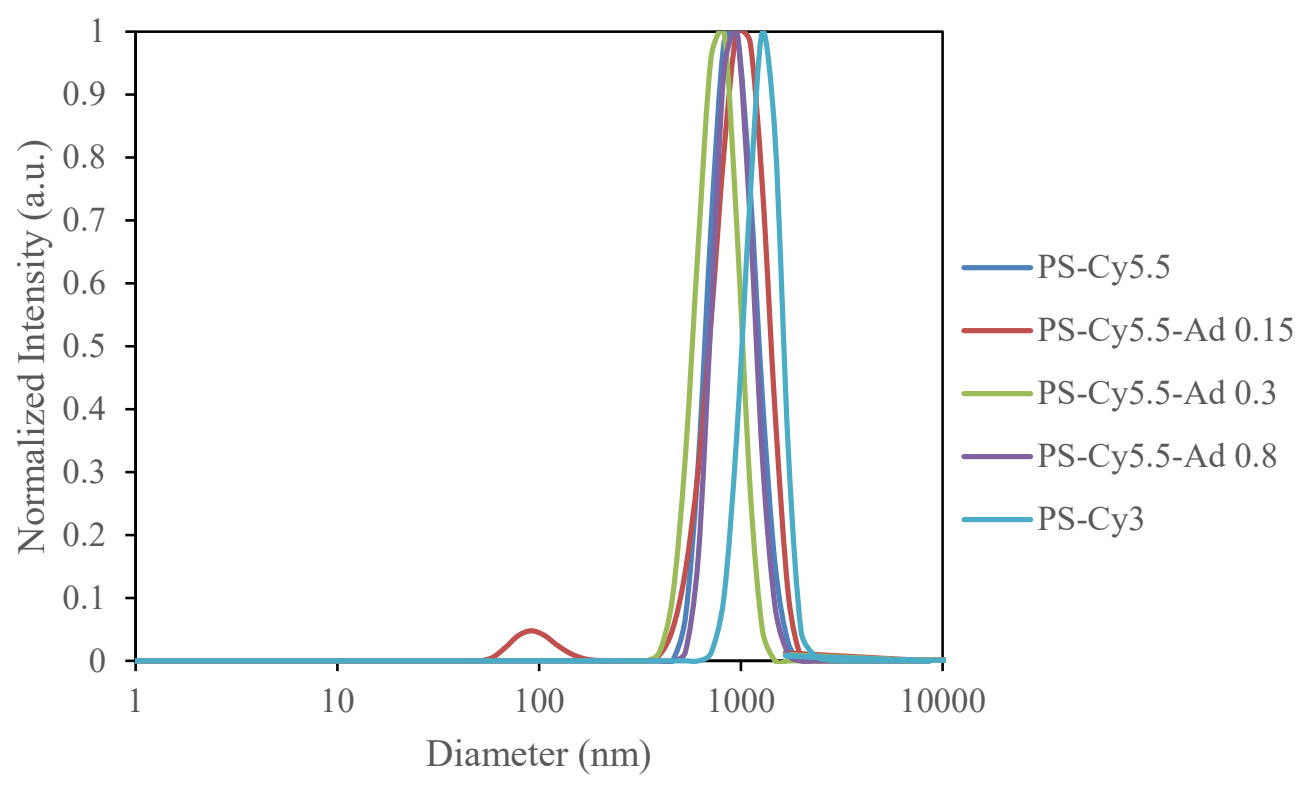

Figure S2: DLS plot of PS particles showing size vs normalized intensity of the different PS particles 


\section{Dimensions of Micronit ${ }^{\circledR}$ flow cell and Comsol flow channel}

a

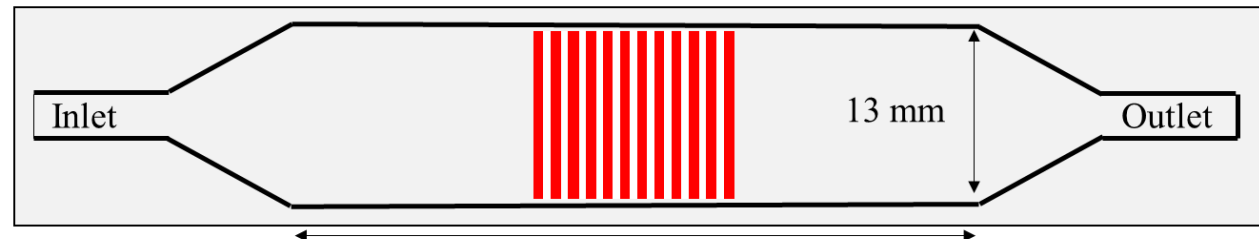

$20 \mathrm{~mm}$

b

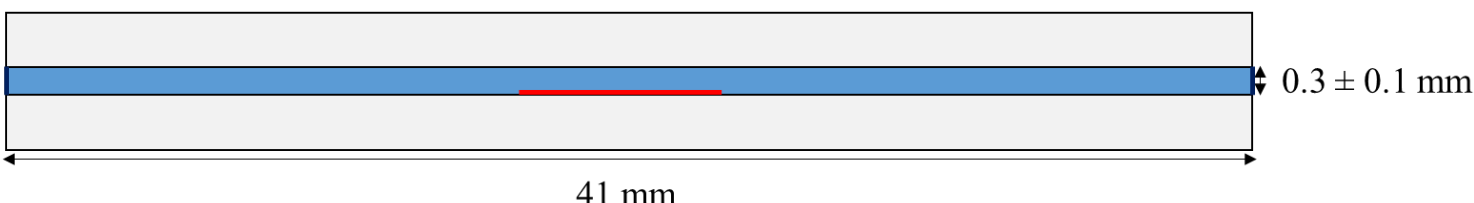

$41 \mathrm{~mm}$

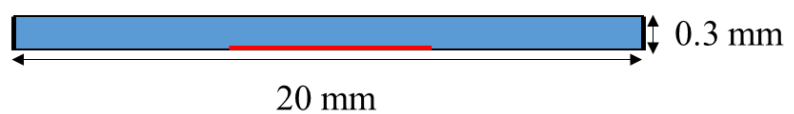

Figure S3: Scheme showing the dimensions of an extended 4515 resealable flow cell purchased from Micronit ${ }^{\circledR}$. a) Top view of the flow cell and b) side view of flow cell showing casket slide on top of an 'empty' slide. The bottom slide is functionalized with patterns of $\beta-\mathrm{CD}$ approximately in the center over a surface area of 10x10 $\mathrm{mm}^{2}$ (marked in red). c) Dimensions of the flow channel used in Comsol showcasing the area (in red) where particles were counted for the quantitative analysis. 


\section{Characterization of $\boldsymbol{\beta}-\mathrm{CD}$ printed Glass Surfaces}

In order to show successful patterning of $\beta-C D$, a validation step using a diadamantane functionalized Cy5 dye (Cy5- $\mathrm{Ad}_{2}$, structure shown in Figure $\left.\mathrm{S} 1\right)$ was implemented. A glass slide microcontact printed with $\beta-\mathrm{CD}$ was placed upside down on $0.28 \mu \mathrm{M}$ of $\mathrm{Cy} 5-\mathrm{Ad}_{2}$ in $1 \mathrm{x}$ PBS and incubated for 15 minutes. The glass slide was then thoroughly rinsed with DI water and dried with nitrogen before imaging on the fluorescence microscope. As observed in Figure

$\mathrm{S} 2$, CD patterns are filled with $\mathrm{Cy} 5-\mathrm{Ad}_{2}$ molecules through host-guest interactions.

a)

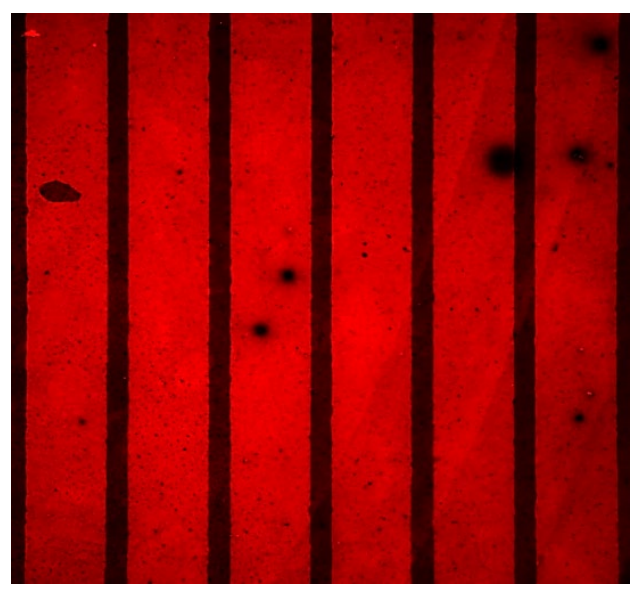

b)

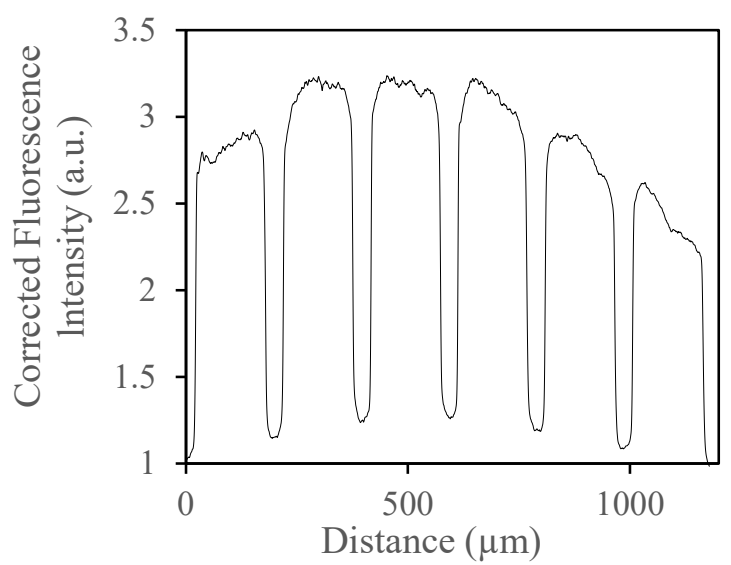

Figure S4: a) Fluorescence image of $\mathrm{Cy} 5-\mathrm{Ad}_{2}$ adhered to $\beta-\mathrm{CD}$ patterns. b) Fluorescence intensity profile of a). 


\section{Determining PS particle concentration}

The concentration of PS particles was determined through freeze drying the PS emulsion after synthesis and washing the particles with DI water. 3 glass vials were weighed and $5 \mathrm{~mL}$ of undiluted PS particles was pipetted into each. After freeze drying the vials were weighed again to determine the mass of the dried PS particle emulsion. From the mass concentration $(\mathrm{g} / \mathrm{mL})$ the amount of particles per $\mathrm{mL}$ can be calculated from the following equation:

$$
\text { Eq. S1: number of particles per } \mathrm{mL}=\frac{6 W \times 10^{12}}{\rho \times \pi \times \sigma^{3}}
$$

Where $\mathrm{W}$ is the grams of polymer per $\mathrm{mL}$ in latex, $\rho$ is the density of polymer in grams per $\mathrm{mL}$ (1.05 for polystyrene) and $\sigma$ is the diameter in microns of polystyrene particles. This equation is derived from dividing mass concentration by the density and from calculating volume of a sphere. The ' 6 ' and ' $10^{12}$, are placed there for simplification and unit conversions. W was determined at $0.100 \pm 0.006 \mathrm{~g} / \mathrm{mL}$ as the average mass concentration from the freeze dried samples. This is equal to $1.82 \times 10^{11}$ particles $/ \mathrm{mL}$. According to literature, ${ }^{1}$ the PS particles have a $\mathrm{COOH}$ parking area of $0.14 \mathrm{~nm}^{2}$, which results in a $\mathrm{COOH}$ concentration of $6.78 \mathrm{mM}$.

Table S1: PS particle characterization based on radius and literature $\mathrm{COOH}$ parking area

\section{PS particle characterization}

Particle radius $(\mu \mathrm{m})$

Surface area $\left(\mu \mathrm{m}^{2}\right)$

Theoretical/Literature parking area per $\mathrm{COOH}\left(\mathrm{nm}^{2}\right)$

Theoretical $\mathrm{COOH}$ groups on surface

Mass concentration $(\mathrm{g} / \mathrm{mL})$ (from freeze drying results)

Particles per $\mathrm{mL}$ 


\section{Reverse conductometric titration of PS particles}

Quantification of the amount of acid groups on the PS particle surface was carried out using reverse conductometric titration. ${ }^{2}$ The $\mathrm{pH}$ of the solution was first increased to $\mathrm{pH} 10$ in order to de-protonate all the $\mathrm{CO}_{2} \mathrm{H}$ groups and then titration with $\mathrm{HCl}$ was carried out. The first stage of the graph corresponds to titration of strong base, the second stage to the titration carboxylate ions $\left(\mathrm{CO}_{2}^{-}\right)$on the PS surface and the third one is due to increase in the $\mathrm{HCl}$ concentration.

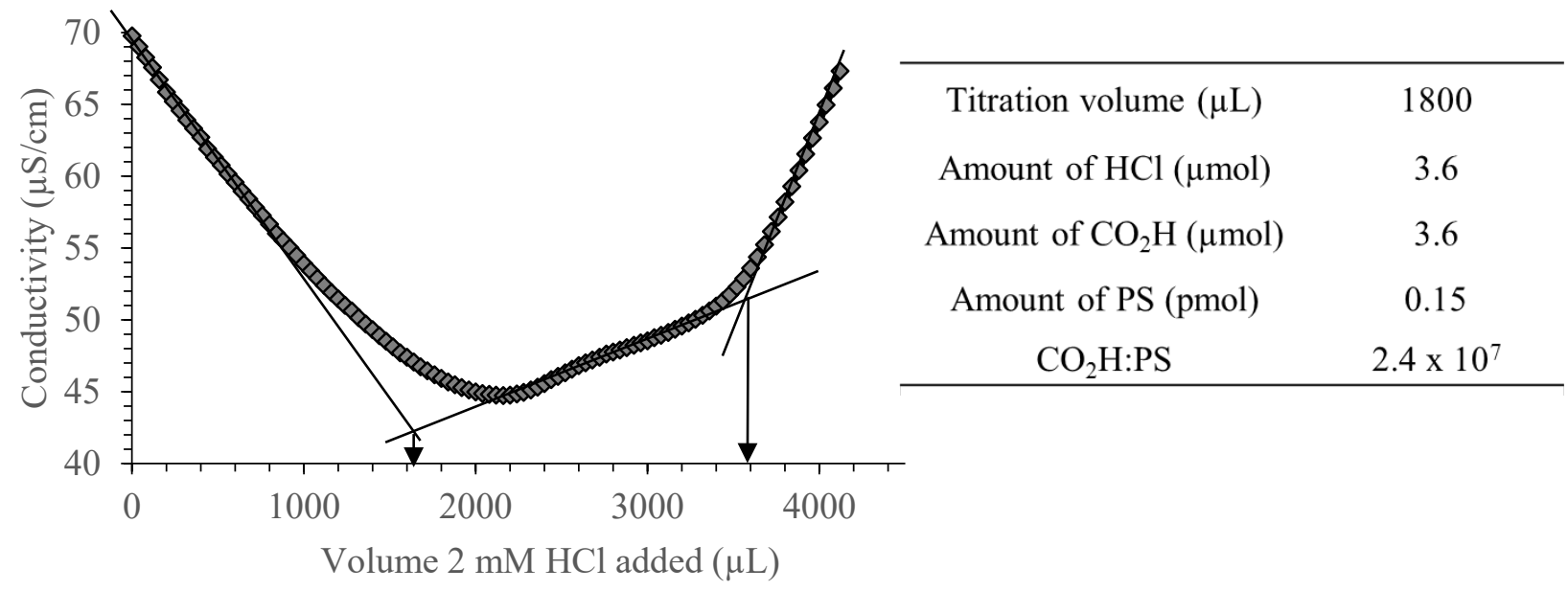

Figure S5: Conductometric titration of PS-Cy5.5 particles with $\mathrm{HCl}$ after deprotonation with $\mathrm{NaOH}$. First arrow marks start of the titration of $\mathrm{CO}_{2} \mathrm{H}$ groups on PS and second arrow the end of the titration. Table on the right shows determination of amount of $\mathrm{CO}_{2} \mathrm{H}$ groups on the particles from the titration volume 


\section{NMR analysis of supernatants from PS-Ad particles}

To quantify the amount of Ad- $\mathrm{NH}_{2}$ that was conjugated to the particles, proton NMR analysis of the supernatant after EDC coupling was carried out. A reference spectrum of $10 \mathrm{mM}$ Ad$\mathrm{NH}_{2}$ was measured to identify characteristic peaks for adamantane and determine the integral of peaks compared to the internal standard ( $1 \mathrm{mM}$ TMSP). This internal standard is calibrated for 9 protons. The peak at $\delta=1.64-1.57 \mathrm{ppm}$ is attributed to 3 protons from adamantane, therefore the acquired integral from spectra (after calibration with the TMSP internal standard) was divided by 3 to give the concentration in $\mathrm{mM}$ of $\mathrm{Ad}-\mathrm{NH}_{2}$ left in the supernatant. This was then converted to $\mu \mathrm{mol}$ based on the $1 \mathrm{~mL} \mathrm{D}_{2} \mathrm{O}$ the dried supernatant was dissolved in.

For determining the non-specific uptake of $\mathrm{Ad}-\mathrm{NH}_{2}$ in the dispersion of PS particles, EDC was omitted during Ad- $\mathrm{NH}_{2}$ coupling for all the concentrations of Ad- $\mathrm{NH}_{2}$ used (Table S2). Non-specific uptake was then calculated as a percentage by comparing the Ad- $\mathrm{NH}_{2}$ amount left in the PS particle suspensions. 


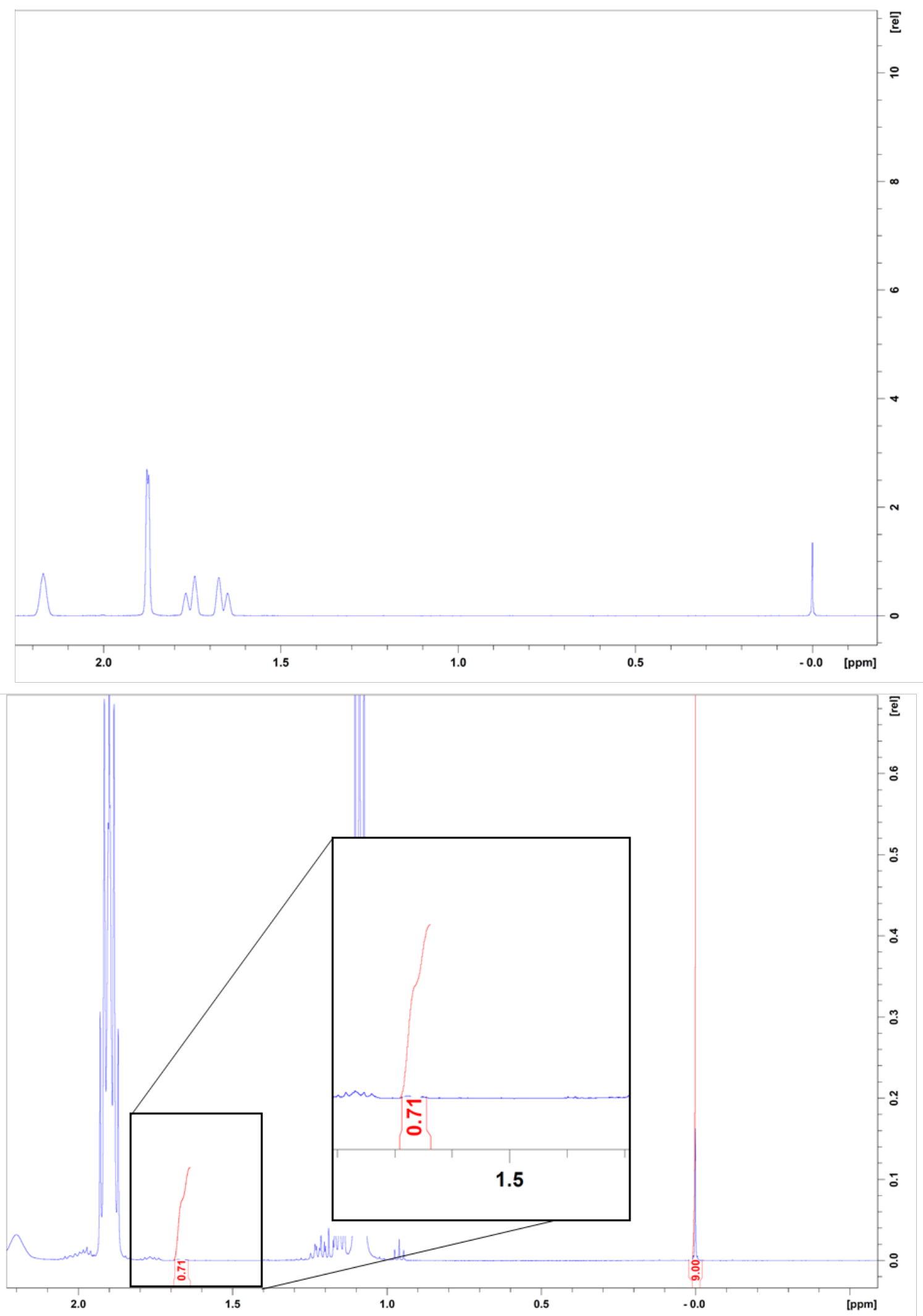

Figure S6: NMR spectra of adamantane amine reference (top) and supernatant of $0.1 \mathrm{mM}$ (bottom) Ad$\mathrm{NH}_{2}$ PS sample 

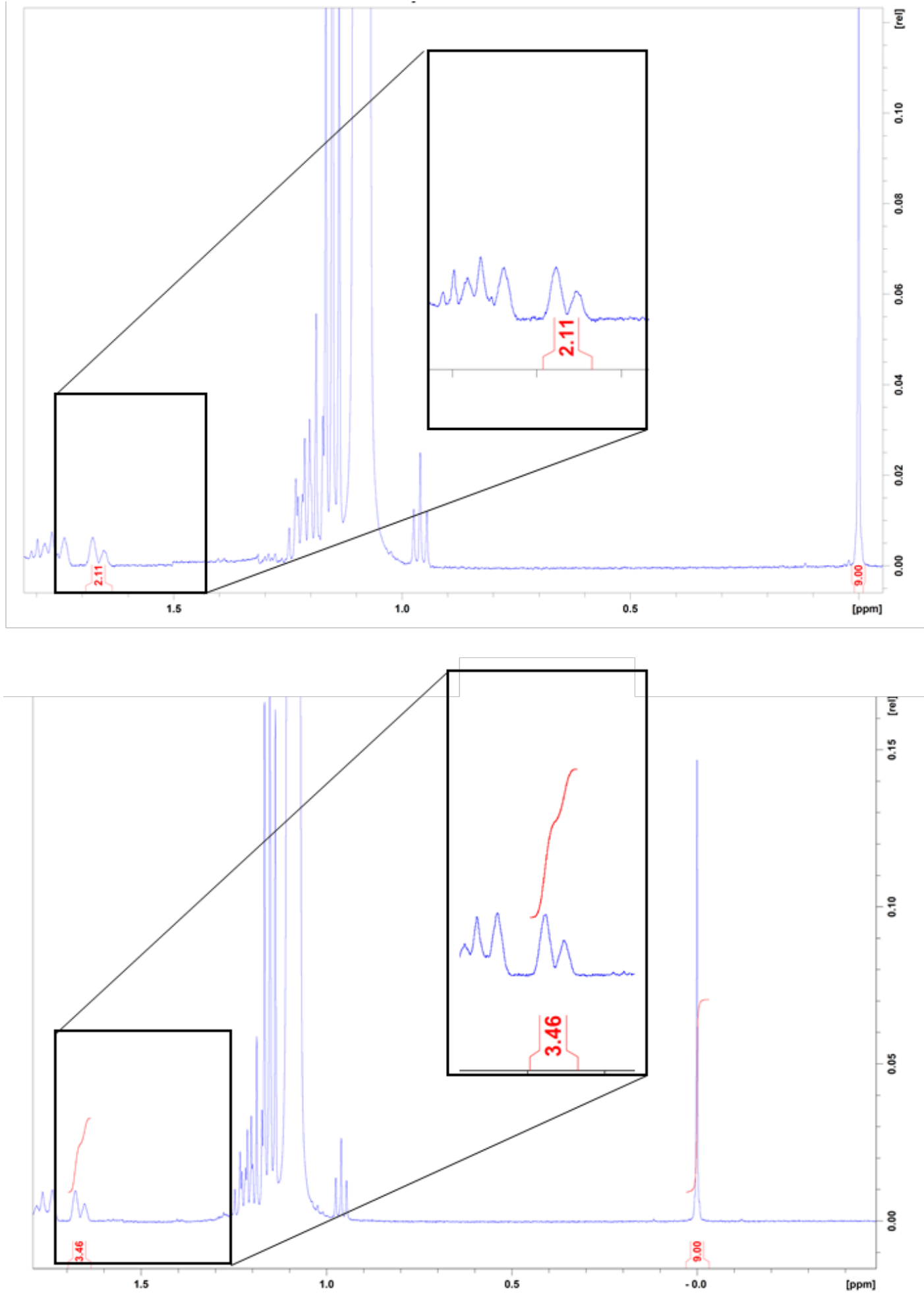

Figure S7: NMR spectra of 0.25 (top) and $0.5 \mathrm{mM}$ (bottom) Ad- $\mathrm{NH}_{2}$ PS supernatant samples 
Table S2: Determining uptake of Ad- $\mathrm{NH}_{2}$ in PS particles without EDC for the different amounts of Ad$\mathrm{NH}_{2}$ added

\begin{tabular}{|c|c|c|c|}
\hline $\begin{array}{l}\text { PS-Cy5.5-Ad control } \\
\text { samples without EDC }\end{array}$ & PS-Cy5.5-0.15Ad & PS-Cy5.5-0.3Ad & PS-Cy5.5-0.8Ad \\
\hline $\begin{array}{c}\text { Ad-NH} \mathrm{NH}_{2} \text { added to PS } \\
(\mu \mathrm{mol})\end{array}$ & 0.53 & 1.33 & 2.67 \\
\hline $\begin{array}{l}\text { Ad-NH }{ }_{2} \text { amount in } \\
\text { supernatant }(\mu \mathrm{mol})\end{array}$ & 0.37 & 1.07 & 2.15 \\
\hline $\begin{array}{c}\text { Ad- } \mathrm{NH}_{2} \text { in PS } \\
\text { suspension }(\mu \mathrm{mol})\end{array}$ & 0.16 & 0.26 & 0.52 \\
\hline $\begin{array}{l}\text { Ad-NH} H_{2} \text { with EDC in } \\
\text { PS suspension }(\mu \mathrm{mol})\end{array}$ & 0.29 & 0.63 & 1.52 \\
\hline $\begin{array}{l}\text { Non-specific uptake of } \\
\text { Ad- } \mathrm{NH}_{2}\end{array}$ & $55 \%$ & $40 \%$ & $34 \%$ \\
\hline
\end{tabular}


Stokes drag force, Reynolds numbers, Péclet number of particles at different flow rates

Stokes law:

$$
\text { Eq. S1: } F_{d}=6 \pi \eta r v
$$

where $F_{d}$ is Stokes Drag $(N), \eta$ is dynamic viscosity $\left(\mathrm{kg} \mathrm{m}^{-1} \mathrm{~s}^{-1}, 0.01\right.$ for water $), r$ is the radius of particle $(\mathrm{m})$ and $\mathrm{v}$ is the flow velocity relative to the particle $\left(\mathrm{m} \mathrm{s}^{-1}\right)$

Table S3: Table showing the average Stokes Drag particles experience at different flow rates

\begin{tabular}{ccc} 
Flow rate $(\boldsymbol{\mu L} / \mathrm{min})$ & Velocity $(\mathbf{m} / \mathbf{s})$ & Stokes Drag $(\mathbf{N})$ \\
\hline 0.125 & $5.35 \times 10^{-6}$ & $5 \times 10^{-15}$ \\
0.25 & $1.07 \times 10^{-6}$ & $1 \times 10^{-14}$ \\
1.25 & $5.35 \times 10^{-6}$ & $5 \times 10^{-14}$ \\
2.5 & $1.07 \times 10^{-5}$ & $1 \times 10^{-13}$ \\
5 & $2.14 \times 10^{-5}$ & $2 \times 10^{-13}$ \\
10 & $4.27 \times 10^{-5}$ & $4 \times 10^{-13}$ \\
100 & $4.27 \times 10^{-4}$ & $4 \times 10^{-12}$ \\
200 & $8.54 \times 10^{-4}$ & $8 \times 10^{-12}$ \\
\hline
\end{tabular}

Reynolds number

$\mathrm{Eq} \cdot \mathrm{S} 2: \operatorname{Re}=\frac{V D_{h}}{v}$

Where $\mathrm{V}$ is average velocity $\left(\mathrm{m} \mathrm{s}^{-1}\right), \mathrm{D}_{\mathrm{h}}$ characteristic length of the flow channel $(\mathrm{m})$ and $\mathrm{v}$ is the kinematic viscosity $\left(\mathrm{m}^{2} \mathrm{~s}^{-1}\right)$. In general, Reynolds numbers below 1 dictate a laminar flow regime:

Péclet number

Eq. S3: $P e=\frac{V_{x} R}{D}$

Where $V_{x}$ is the speed of the particles at a certain height, $R$ is the height from the channel wall $(\mathrm{m})$, and $\mathrm{D}$ is the diffusivity $\left(\mathrm{m}^{2} \mathrm{~s}^{-1}\right)$ 


$$
\text { Eq. S4: } D=\frac{k T}{6 \pi \eta r}
$$

Where $\mathrm{k}$ is Boltzmann's constant, $\mathrm{T}$ is temperature $(\mathrm{K}), \eta$ is the dynamic viscosity $\left(\mathrm{kg} \mathrm{m}^{-1} \mathrm{~s}^{-}\right.$ ${ }^{1}$ ), and $\mathrm{r}$ is the radius of particle $(\mathrm{m})$

The diffusivity for the particles is $4.29 \times 10^{-13} \mathrm{~m}^{2} \mathrm{~s}^{-1}$ regardless of the flow rate, while the flow velocity of the particles at $1 \mu \mathrm{m}$ height above the channel wall is 0.0132 times the average flow velocity of particles within the channel.

Table S4: Table showing average flow velocity, Reynolds number, flow velocity at $1 \mu \mathrm{m}$ height above channel wall and Peclet number at $1 \mu \mathrm{m}$ height above channel wall

\begin{tabular}{ccccc}
$\begin{array}{c}\text { Flow rate }(\boldsymbol{\mu L} / \\
\text { min) }\end{array}$ & $\begin{array}{c}\text { Average flow } \\
\text { velocity }(\boldsymbol{m} / \mathbf{s})\end{array}$ & $\begin{array}{c}\text { Reynolds } \\
\text { number }\end{array}$ & $\begin{array}{c}\text { Flow velocity } \\
\boldsymbol{1} \boldsymbol{\mu m} \text { height }(\boldsymbol{m} / \mathbf{s})\end{array}$ & $\begin{array}{c}\text { Péclet } \\
\text { number }\end{array}$ \\
\hline 0.125 & $5.35 \times 10^{-6}$ & 0.00025 & $1.42 \times 10^{-8}$ & 0.03 \\
0.25 & $1.07 \times 10^{-6}$ & 0.0005 & $2.84 \times 10^{-8}$ & 0.07 \\
1.25 & $5.35 \times 10^{-6}$ & 0.0025 & $1.42 \times 10^{-7}$ & 0.33 \\
2.5 & $1.07 \times 10^{-5}$ & 0.005 & $2.84 \times 10^{-7}$ & 0.66 \\
5 & $2.14 \times 10^{-5}$ & 0.010 & $5.68 \times 10^{-7}$ & 1.32 \\
10 & $4.27 \times 10^{-5}$ & 0.021 & $1.14 \times 10^{-6}$ & 2.64 \\
100 & $4.27 \times 10^{-4}$ & 0.21 & $1.14 \times 10^{-5}$ & 26.4 \\
200 & $8.54 \times 10^{-4}$ & 0.42 & $2.28 \times 10^{-5}$ & 52.8 \\
\hline
\end{tabular}




\section{Flow of PS particle mix over glycine printed flow cells}

Glycine was microcontact printed on an isothiocyanate coated flow cell similar to $\beta$-CD glass surface functionalization protocol. The flow cells were also backfilled with PEG. PS-Cy5.50.8Ad and PS-Cy3 particles were flowed over glycine printed flow cells at $5 \mu \mathrm{L} / \mathrm{min}$ for 60 minutes. After flow incubation the flow cell was run dry and the surface was imaged with fluorescence microscopy. The images shows no visible patterned binding to the glycine prints on the glass surface from either particle species.
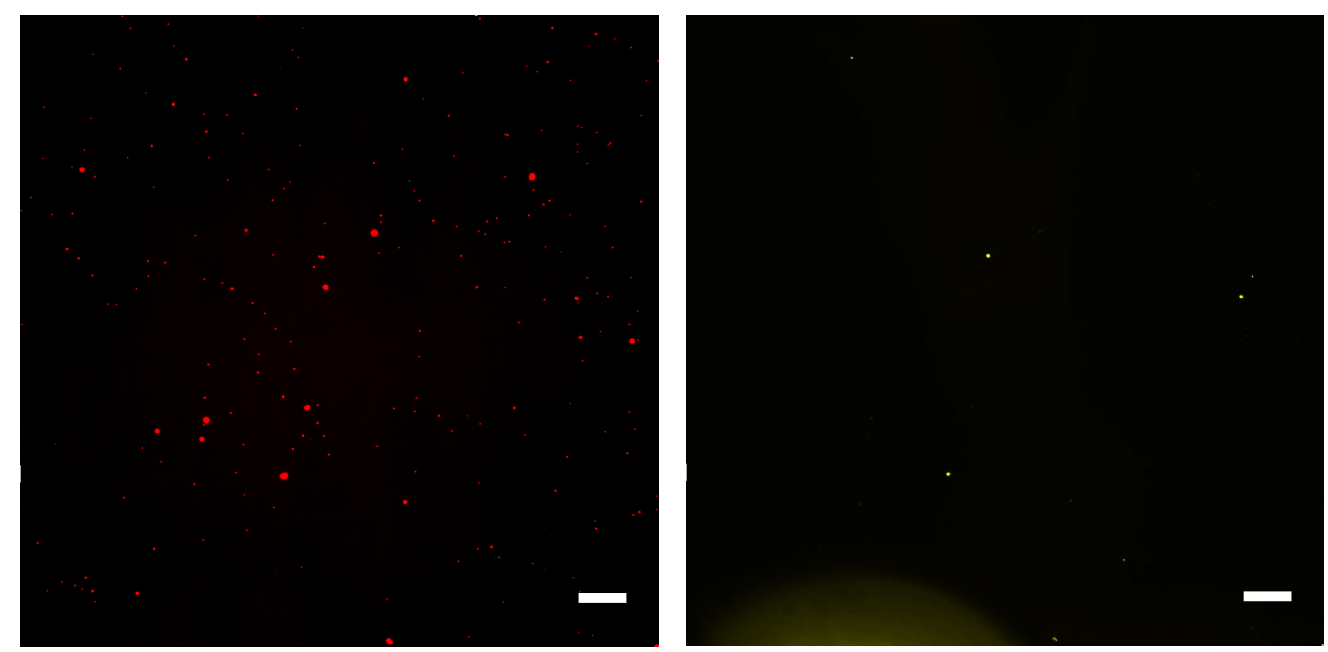

Figure S8: Microscope images of glycine printed flow cells after addition of PS particles mix at $5 \mu \mathrm{L} / \mathrm{min}$. Left image shows PS-Cy5.5-Ad particles and right images show PS-Cy3 particles 
All flow rate variation experiments for PS-Cy5.5-0.8Ad and PS-Cy3 particles over $\beta$-CD printed surfaces

a)
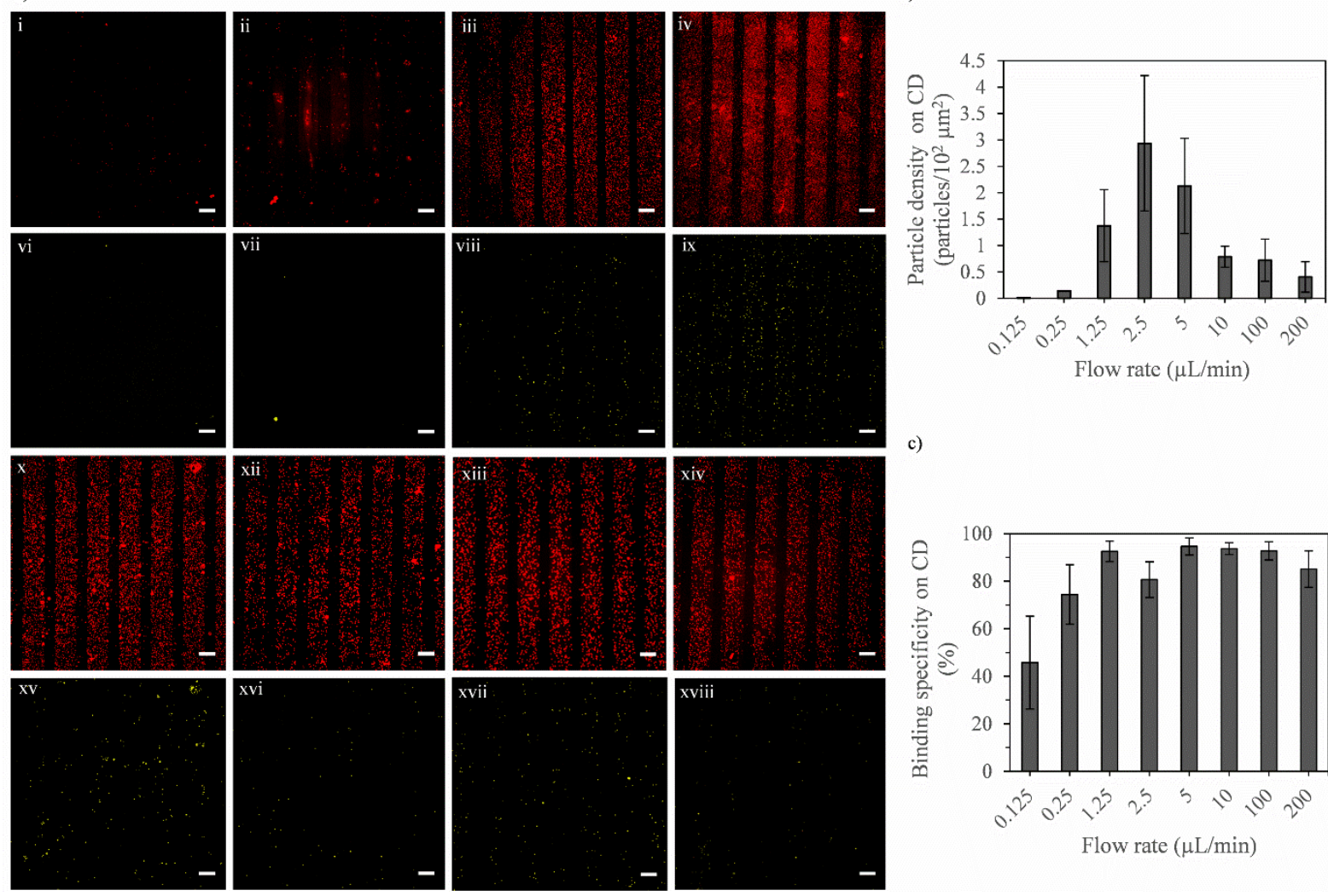

c)

Flow rate $(\mu \mathrm{L} / \mathrm{min})$
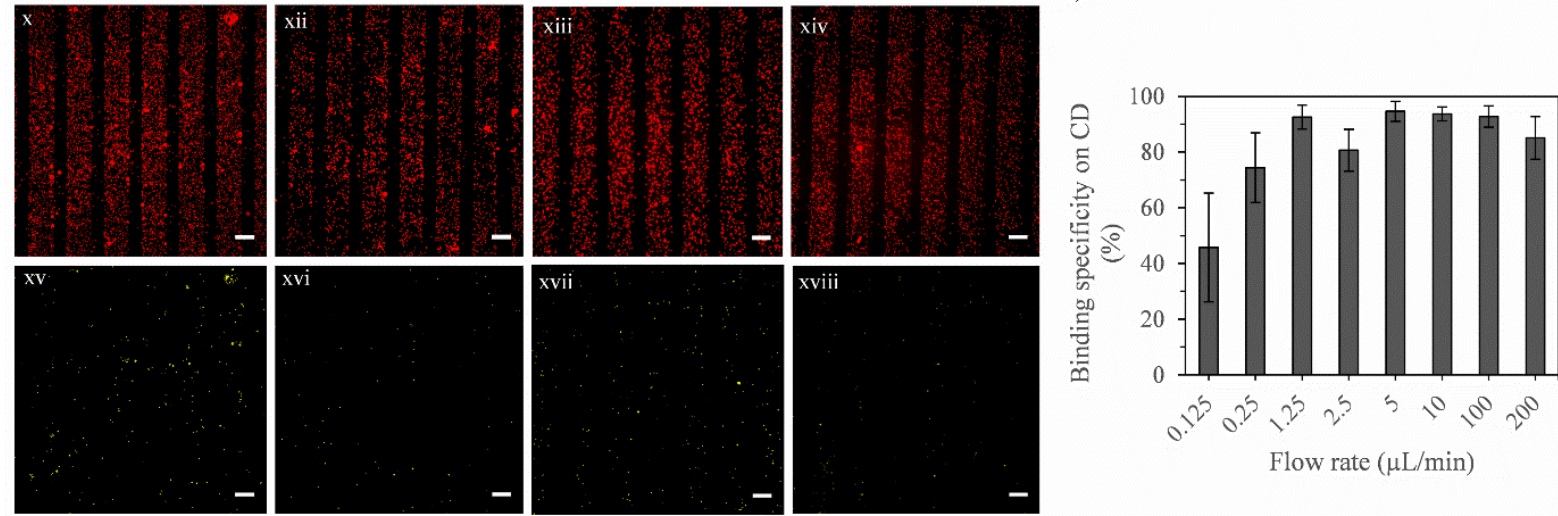

Figure S9: a) Fluorescence images of $\beta-C D$ platforms after addition of an equimolar mix of fluorescent polystyrene particles PS-Cy5.5-0.8Ad (i-iv, x-xiv) and PS-Cy3 (vi-ix, xv-xvii). Flow rates used are 0.125 (i,vi) 0.25 (ii,vii), 1.25 (iii, xvii), 2.5 (iv, ix), 5 (x,xv), 10 (xii, xvi), 100 (xiii, xvii) and 200 (xiv, xviii) $\mu \mathrm{L} / \mathrm{min}$. Top images are captured with Cy5 filter and bottom images with RHOD filter at the same location on the surface for the respective flow rate. All scale bars are $100 \mu \mathrm{m}$. b) Graph showing the PS-Cy5.5-Ad particle density on $\beta$-cyclodextrin patterns versus all the flow rates used. c) graph showing the binding specificity for these respective patterns versus the flow rate. 


\section{PS particle distribution after $0.25 \mu \mathrm{L} / \mathrm{min}$ flow rate of 20 hours}
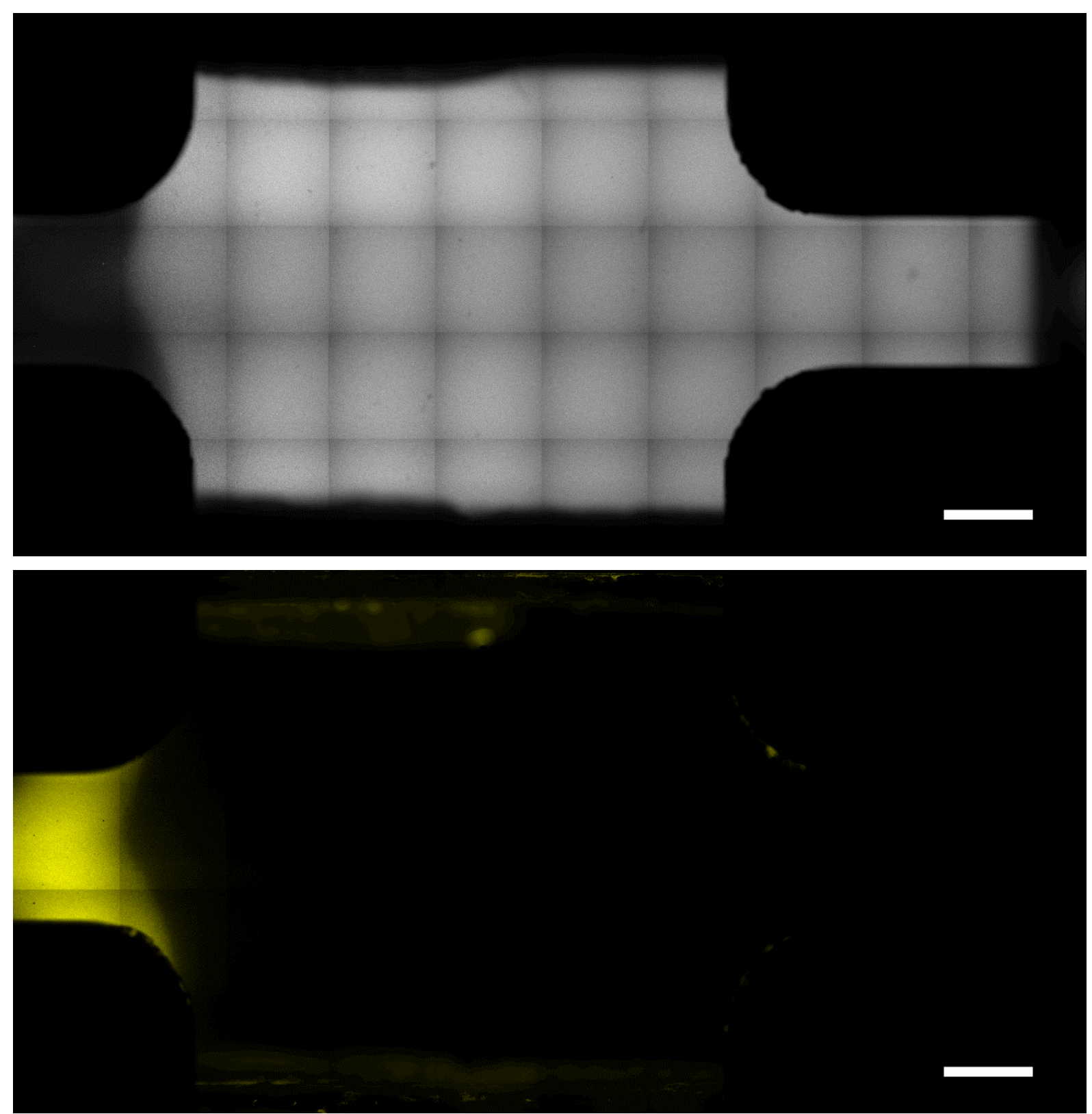

Figure S10: Overview of extended area (13 mm width) of flow channel after flow incubation of PS-Cy3 particles at $0.25 \mu \mathrm{L} / \mathrm{min}$ for 20 hours over a PEG functionalized glass surface. Captured with $5 \mathrm{x}$ objective and using 10x 5 tilescan. Top image shows the brightfield image while the bottom image shows the RHOD filter. The dark round edges in the corners of the brightfield image are attributed to Micronit flow cell holder, not the flow channel path. Scale bars are $2 \mathrm{~mm}$. 


\section{Distance above the wall for particles at $\mathrm{Pe}=1$ condition}

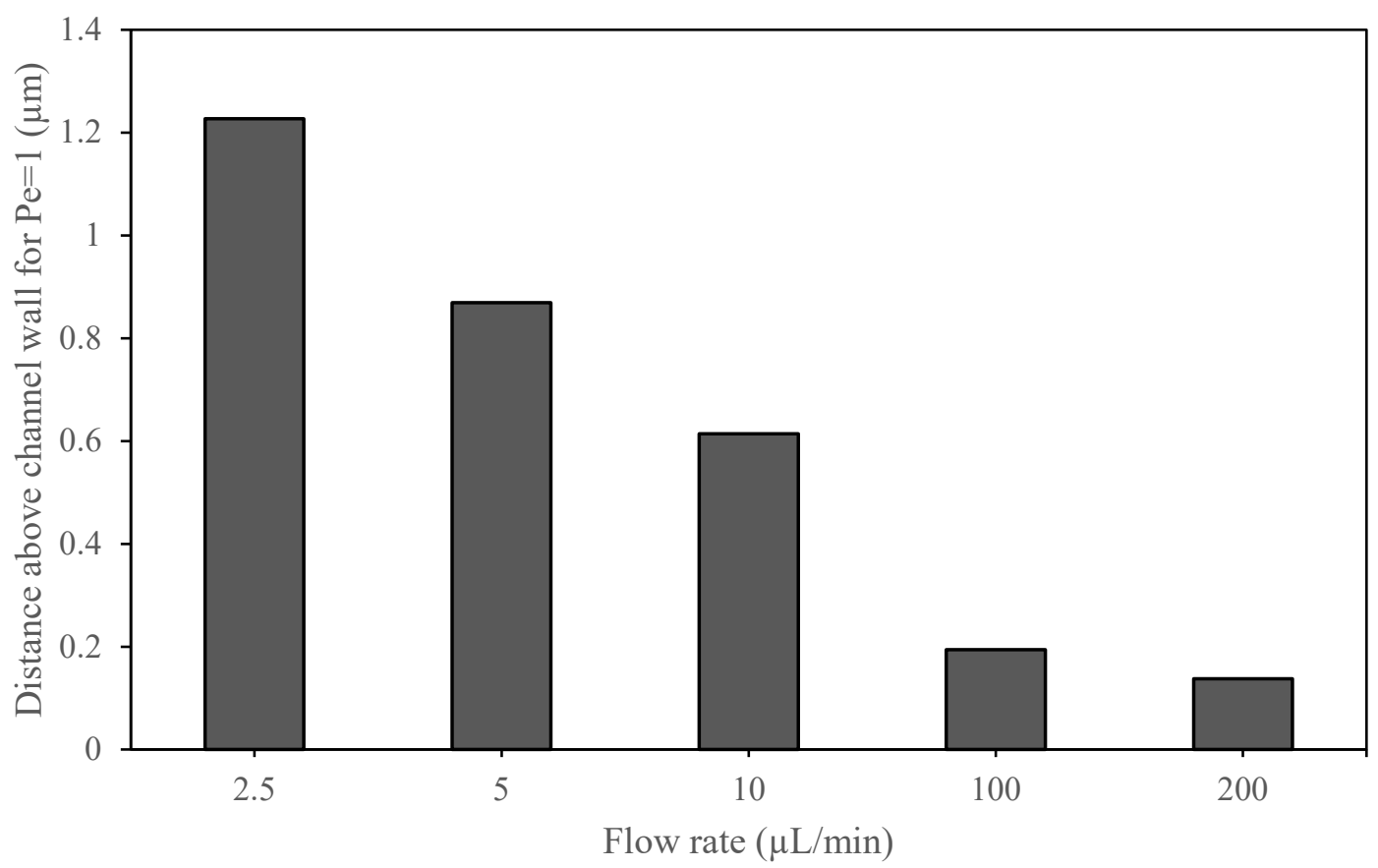

Figure S11: Graph showing the distance above the wall for the condition that $\mathrm{Pe}=1$ versus the flow rate used.
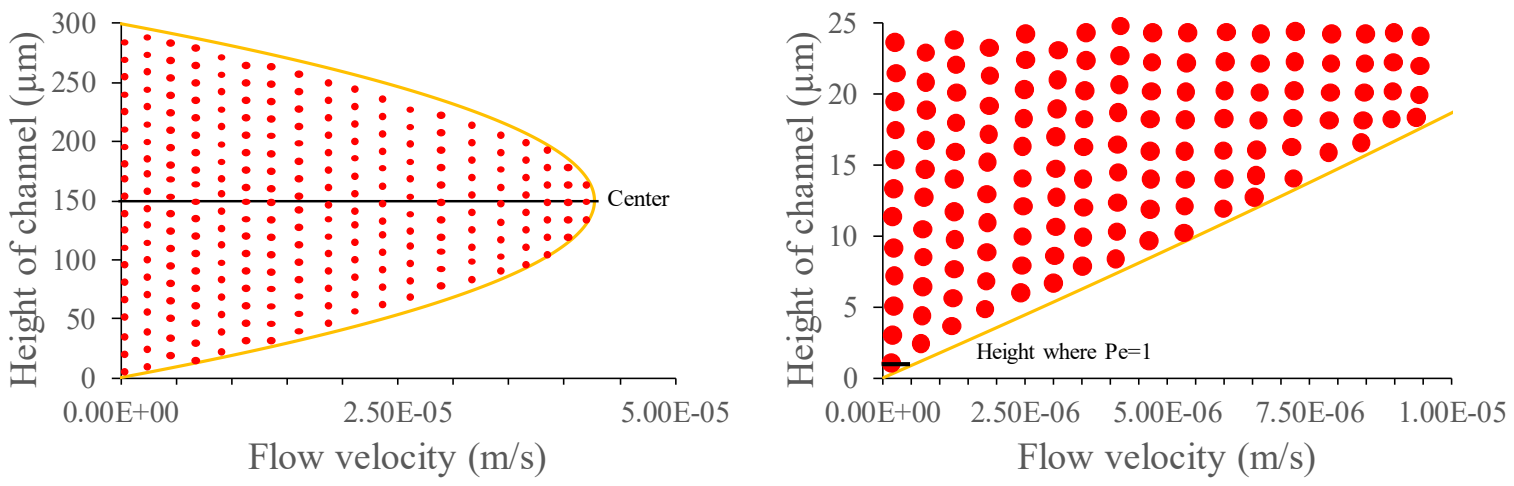

Figure S12: An example of how particles are spread throughout laminar flow at flow rate $5 \mu \mathrm{L} / \mathrm{min}$ of solution and which part of the solution is most likely to come into contact with the surface based on Peclet number. Graph on the left shows the whole channel height while the graph on the left is zoomed in to showcase the height where $\mathrm{Pe}=1$ 
Quantitative analysis of PS-Cy3 particle density (in PS particle mix) with different flow rates of PS particle mix solution and different Ad loadings on PS-Cy5.5-Ad

The nonselective binding of PS-Cy3 particles with the functionalized glass platforms were quantified and compared with different parameters of the flow cell experiments, namely the flow rate used and the Ad loading PS-Cy5.5-Ad. Particle density of PS-Cy3 on $\beta$-CD lines are in general ca 100 times lower than their PS-Cy5.5-Ad counterparts. Nevertheless, an increase in PS-Cy3 particle density is seen with higher Ad loading on PS-Cy5.5-Ad, and a decrease between 2.5 and $200 \mu \mathrm{L} / \mathrm{min}$ flow rate (Figure S14).
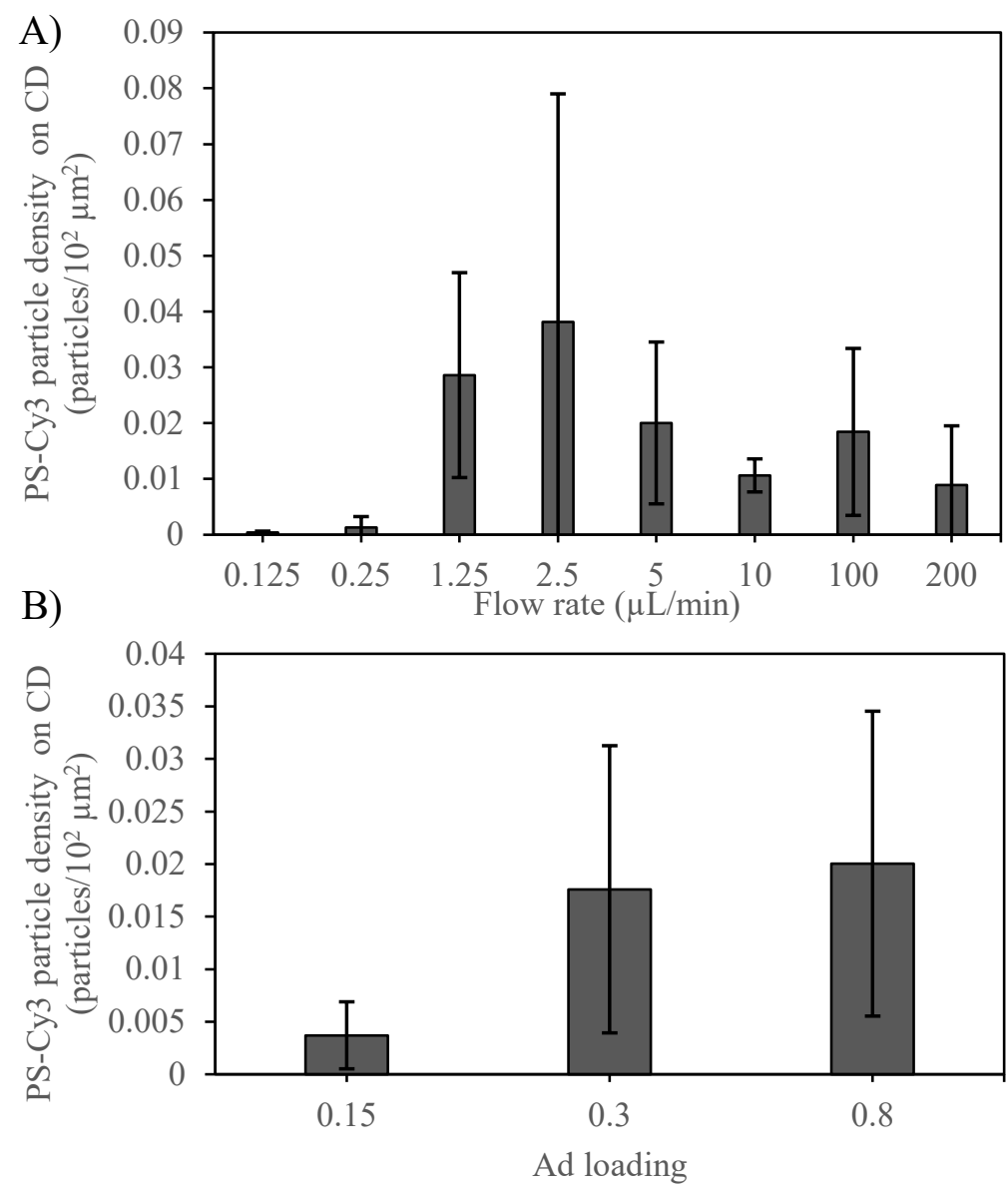

Figure S11: Graphs showing the effect of PS-Cy3 particle density on $\beta$ CD lines comparied with A) the flow rate of the PS particles mix solution B) the Ad loading on PS-Cy5.5-Ad. 


\section{Flow of PS-Cy3 particles over $\beta$-CD printed surface}

Non-functionalized PS-Cy3 particles were flowed over CD printed surfaces at a flow rate of 5 $\mu \mathrm{L} /$ min for 60 minutes and then imaged with the fluorescence microscope after running dry. As shown in Figure S15, no visible patterned binding is observed for the non-functionalized PS-Cy3 particles when PS-Cy5.5-Ad particles are not present.

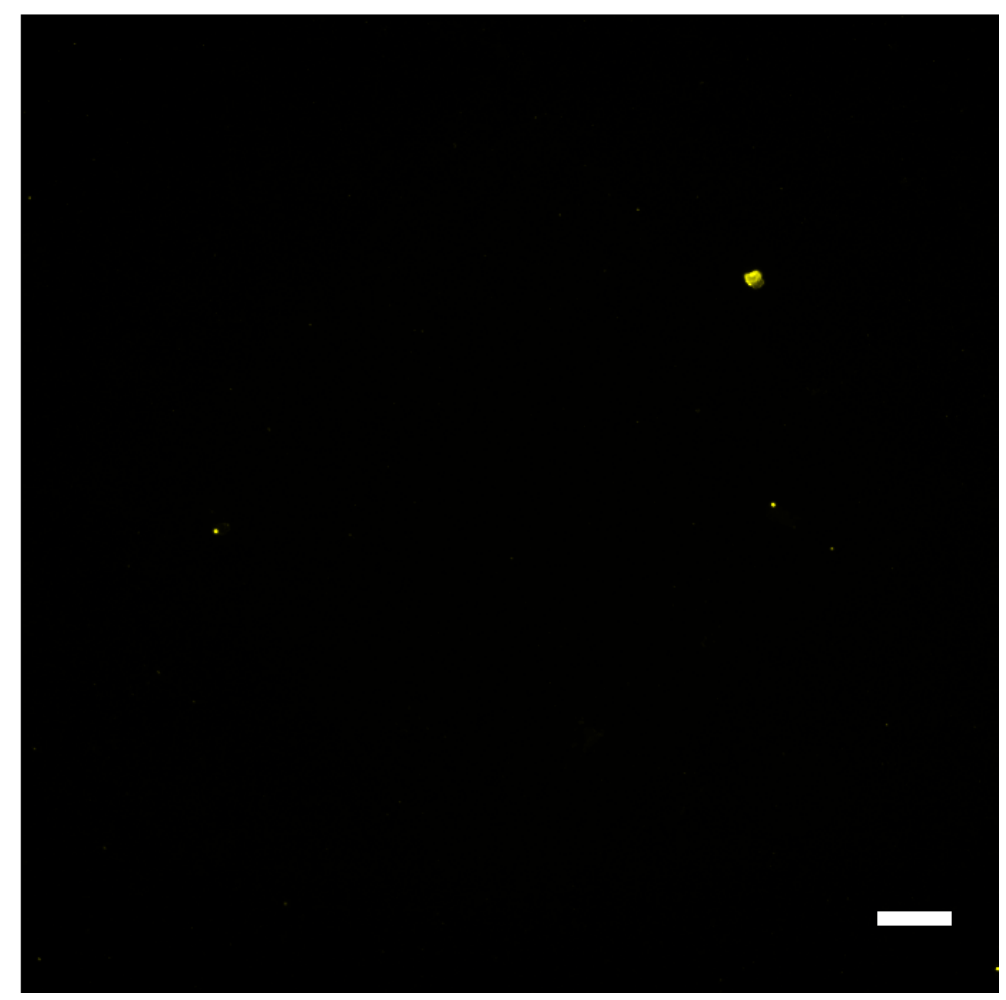

Figure S12: Fluorescence image of $5 \mu \mathrm{L} / \mathrm{min}$ addition of PS-Cy3 over $\beta$-CD patterns. Scale bar is $100 \mu \mathrm{m}$. 


\section{REFERENCES}

1. Appel, J.; Akerboom, S.; Fokkink, R. G.; Sprakel, J. Facile One-Step Synthesis of Monodisperse Micron-Sized Latex Particles with Highly Carboxylated surfaces. Macromol Rapid Commun 2013, 34 (16), 1284-1288.

2. Hen, J. Determination of Surface Carboxyl Groups in Styrene/Itaconic Acid Copolymer Latexes. J. Colloid Interface Sci. 1974, 49 (3), 425-432. 